\title{
Fading out of view: the enigmatic decline of Rose's mountain toad Capensibufo rosei
}

\author{
E. R. Cressey, G. J. Measey and K. A. Tolley
}

\begin{abstract}
Rose's mountain toad Capensibufo rosei survives in a few isolated montane populations in the south-western Cape of South Africa. It comprises several cryptic species but it is uncertain whether the lineage on the Cape Peninsula is distinct. We tested the hypothesis that toads from the Peninsula form a single genetic lineage but that different breeding sites are divergent at a population level as a result of limited dispersal abilities. Directed surveys were carried out to locate breeding sites and samples obtained were analysed in a phylogenetic and population genetic framework, using two mitochondrial markers. We found toads breeding at only one of five known historical breeding sites, although one new breeding site was also recorded. No toads were observed at 15 other non-breeding localities where they were historically observed. Toads from the two active breeding sites formed a single lineage that was sufficiently distinct to be given species status. However, these were discrete at a population level, with no shared haplotypes, suggesting no gene flow between sites. One site was particularly low in genetic diversity, implying increased vulnerability to stochastic events and elevated risk of extinction. These results, coupled with the failure to locate historically known sites on the Cape Peninsula, make this newly recognized Peninsula endemic a conservation priority. Efforts should focus on the protection and expansion of the two known surviving populations and the patches of habitat upon which they rely.
\end{abstract}

Keywords Amphibian, Bufonidae, Cape Floristic Region, Cape Fold Mountains, dwarf toads, extinction risk, fynbos biome

This paper contains supplementary material that can be found online at http://journals.cambridge.org

E. R. CRESSEY* Applied Biodiversity Research Division, South African National Biodiversity Institute, Claremont, South Africa

G. J. MeAsEy Department of Zoology, Nelson Mandela Metropolitan University, Port Elizabeth, South Africa

K. A. Tolley $\dagger$ (Corresponding author) Applied Biodiversity Research Division, South African National Biodiversity Institute, Private Bag X7, Claremont 7735, South Africa. E-mail: k.tolley@sanbi.org.za

*Also at: Percy FitzPatrick Institute of African Ornithology, University of Cape Town, Rondebosch, South Africa

$\dagger$ Also at: Department of Botany and Zoology, University of Stellenbosch, Matieland, South Africa

Received 7 February 2013. Revision requested 22 May 2013.

Accepted 15 July 2013. First published online 11 February 2014

\section{Introduction}

A midst growing concern over the biodiversity crisis $\mathrm{A}_{\text {and }}$ the suggestion that we are currently experiencing the sixth mass extinction, declines in amphibian species are significant. More than one third of amphibians are in decline, with proportionately more species at risk of extinction than any other taxonomic group (Stuart et al., 2004). Furthermore, data pertaining to amphibian declines are probably underestimates because of the large number of poorly studied species (Stuart et al., 2004). Although there is no single factor that explains amphibian declines, habitat destruction and alteration are commonly cited as the most significant threat (Collins \& Storfer, 2003; Beebee \& Griffiths, 2005; Measey, 2011). Some declines represent a phenomenon that goes beyond these observable causes, occurring in areas that are protected and/or relatively pristine (Stuart et al., 2004). Such enigmatic declines are more difficult to redress and reveal inadequacies in our understanding of species as well as our approaches towards habitat protection (Collins \& Storfer, 2003).

A dearth of baseline data on the population dynamics of amphibians and the relatively brief and anecdotal nature of many studies have led to difficulties in discerning between natural population fluctuations and humaninduced declines (Barinaga, 1990; Pechmann et al., 1991). As a result, mitigation measures are often delayed and this has probably led to the demise of numerous amphibian populations and in some cases entire species (Pounds \& Crump, 1994). In the absence of long-term quantitative data biologists use information on historical distribution and abundance garnered from museum records or naturalhistory databases (Kress et al., 2001). Although such data typically lack information on observed absences, historical presences can direct current search efforts (Skelly et al., 2003).

Capensibufo Grandison, 1980 (Anura: Bufonidae) is a genus of African dwarf toad that consists of two recognized species, $C$. rose $i$ and the allopatric $C$. tradouwi. Both species are isolated on montane plateaux in the Cape Fold Mountains of South Africa, within the fynbos habitat, a Mediterranean-type heathland that characterizes these mountains (Fig. 1). C. rosei is categorized as Vulnerable on the IUCN Red List (SA-FRoG, 2010) and a recent national strategic exercise prioritized this species for conservation work relating to surveying, monitoring and taxonomy (Measey et al., 2011). A recent phylogeny of C. rosei and its congener $C$. tradouwi shows divergences consistent with 

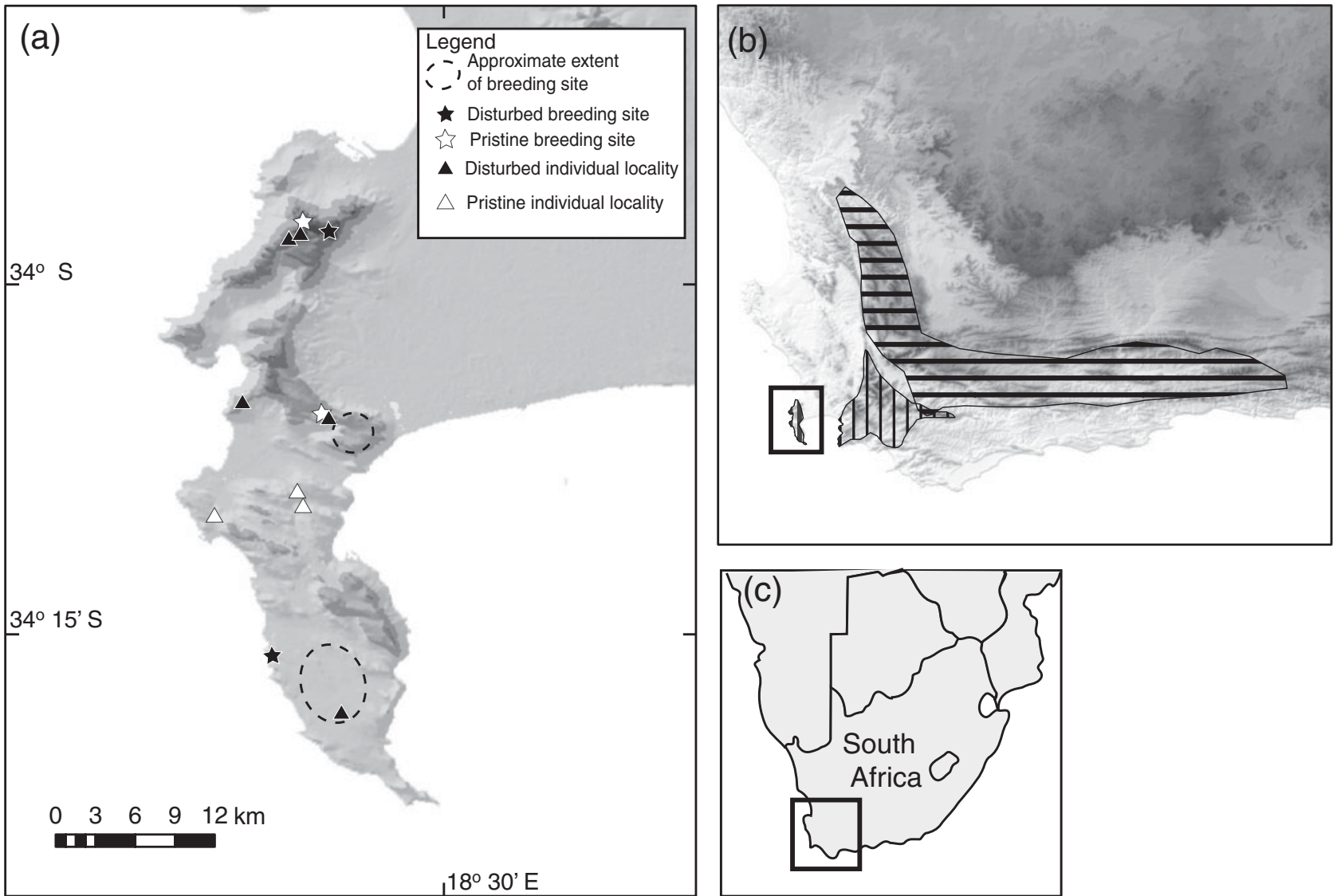

FIG. 1 (a) Historical breeding sites of Rose's mountain toad Capensibufo rosei on the Cape Peninsula, South Africa. (b) The horizontal cross-hatching shows the presumed distribution of $C$. tradouwi and the vertical cross-hatching shows the presumed distribution of C. rosei incertae sedis, with C. rosei distributed only on the Cape Peninsula. The rectangle on (c) indicates the location of (b) and the rectangle on (b) indicates the location of (a).

multiple species and suggests that $C$. rosei sensu lato comprises cryptic species (Tolley et al., 2010). Presumably all populations on the isolated Cape Peninsula represent a single clade but this conclusion is based on only two individuals from a single breeding site (Tolley et al., 2010). It appears that the current conservation status of $C$. rosei was assessed using insufficient taxonomic knowledge, exacerbated by the lack of distributional data as a result of the cryptic nature of these toads. Unlike most other anurans C. rosei has no call (Grandison, 1980) so all records are based on direct observations of individuals. Its montane distribution, small body size $(<2 \mathrm{~cm})$ and cryptic colouration coupled with densely vegetated habitat and a short breeding season (c. 2 weeks in late August) have resulted in a paucity of records (Minter et al., 2004).

To verify the geographical distribution of C. rosei on the Cape Peninsula and to examine possible trends of population persistence, gain and loss we compiled all historical records from the Cape Peninsula and carried out dedicated surveys to locate breeding populations. We also examined the hypothesis that all breeding sites on the Cape Peninsula form a monophyletic clade at the species level (using mitochondrial markers, $\mathrm{ND}_{2}$ and ${ }_{16}$ ) but that these breeding sites are distinct at the population level. Levels of genetic diversity at each breeding site were assessed to highlight the potential vulnerability of Capensibufo spp. to environmental change (e.g. stochastic events) and risk of extinction. The combination of phylogenetic and population genetic analyses, with the examination of historical records, allowed a critical assessment of the current distribution of C. rosei, which has implications for setting conservation priorities for this species.

\section{Methods}

To direct the search effort, historical records from museums and the literature were compiled from the Global Biodiversity Information Facility as well as directly from relevant institutions. Records from the Atlas and Red Data Book of the Frogs of South Africa, Lesotho and Swaziland (Minter et al., 2004) were also included, as were field notes and anecdotal information from local herpetologists. We assumed that records of individual adults probably represented nearby breeding populations at the time they were recorded. Teams of 1-8 people searched 12 historically recorded sites (Supplementary Table 1) on at least 26 
occasions over 4 years (2008-2011). Each search lasted c. 4 hours and was carried out during daylight, when the likelihood of sighting toads or tadpoles was greatest (Fig. 1). This toad does not produce any breeding call and therefore the breeding aggregations are silent both day and night (GJM \& KAT, pers. obs.). C. rosei breeds in ephemeral pools filled by winter rainfall (de Villiers, 2004), typically located on mountain plateaux (Supplementary Table 1). The sites on the Cape Peninsula are characterized by low fynbos vegetation $(<0.5 \mathrm{~m})$ and observers were able to look directly into any small seepage pools. Target areas were scoured, such that all pools were examined for any evidence of aggregating or individual toads and/or spawn and tadpoles, and stones that could provide refuge to adult toads were lifted. To maximize detection, searching began during the breeding season (mid to late August), when dense aggregations of adults form for c. 2 weeks. Searching for pools containing spawn and tadpoles continued until the end of October, when metamorphosis occurs (de Villiers, 2004).

Only two breeding sites were located on the Cape Peninsula, at Silvermine Nature Reserve and Cape of Good Hope Nature Reserve (hereafter referred to as Cape Point; Fig. 1), both of which were sampled for genetic analysis. Toe clips were taken from toads at Silvermine $(n=31)$ and Cape Point $(\mathrm{n}=29)$ in 2011 and stored in 99\% ethanol. Total genomic DNA was extracted using the DNeasy Tissue Kit (Qiagen, Valencia, USA). Portions of two mitochondrial markers, NADH dehydrogenase subunit 2 (ND2) 535 bp and $16 \mathrm{~S}$ ribosomal RNA (16S) $508 \mathrm{bp}$, were amplified by polymerase chain reaction (PCR) in $25 \mu \mathrm{L}$ reaction volumes containing $0.3 \mathrm{mM}$ of dNTPs, $2.5 \mathrm{mM}$ of $\mathrm{MgCl}_{2}, 0.3 \mu \mathrm{M}$ of both forward and reverse primers, 0.25 units (ND2) and 0.2 units (16S) of Taq, and $2.0 \mu \mathrm{L}$ of DNA extract $(25-45 \mathrm{ng} / \mu \mathrm{L})$. ND2 was amplified using the primers vMet2 and vTrp (Cunningham \& Cherry, 2004) and 16S was amplified using the primers $16 \mathrm{Sa}$ and $16 \mathrm{Sb}$ (Palumbi et al., 1991) or $16 \mathrm{SaL}$ to $16 \mathrm{SbH}$ (Vences et al., 2005). PCR products were sent to Macrogen, Korea, for sequencing, and alignments were generated using Geneious Pro 4.7 (Drummond et al., 2009). Sequences were deposited in the EMBL nucleotide sequence database (16S: HG321460-HG321469 and ND2: HG321470HG321482; Supplementary Table 2).

To determine the taxonomic placement of the Cape Peninsula breeding sites a dataset with both markers was constructed, using five individuals per breeding site plus sequences of 30 individuals from the species-level phylogeny (Tolley et al., 2010). Prior to analysis jModelTest v. 0.1.1 (Posada, 2008) was run for each marker to investigate the evolutionary model that best fit the data set, using a likelihood optimization function. For both markers Akaike's information criterion (Akaike, 1973) indicated that the $\operatorname{TrN}+\mathrm{G}$ substitution model (Tamura \& Nei, 1993) was the best fit. Phylogenetic analysis of 1,043 characters was performed using Bayesian inference in MrBayes v. 3 (Ronquist \& Huelsenbeck, 2003). The data were partitioned by marker, with priors specifying six rate categories plus gamma. Markov chain Monte Carlo was run twice in parallel with four independent chains starting from different initial random trees, for 10 million generations. Trees were sampled every 1,00o generations and the first 3 million generations were removed as burn-in. Burn-in was determined by examining the standard deviation of split frequencies for stabilization and whether the effective sample size was $>200$ for all parameters, using Tracer v. 1.4.1 (Rambaut \& Drummond, 2007). A 50\% majority rule tree was constructed and nodes with $\geqslant 0.95$ posterior probability were considered supported. A partitioned maximum likelihood search was run in $R A x M L$ v.7.2.8 (Stamatakis, 2006) at the CIPRES Science Gateway (Miller et al., 2010), using the same partitions and model as the Bayesian analysis plus automatic halting of bootstrapping (Stamatakis, 2006; Stamatakis et al., 2008). Nodes with a bootstrap value of $\geqslant 70 \%$ were considered supported in this analysis.

Population genetics methods were used to examine the genetic structure of the two located breeding sites on the Cape Peninsula, in Arlequin v. 3.1.1 (Excoffier et al., 2005). Haplotype diversity $(h)$ and nucleotide diversity $(\pi)$ were estimated. Population structure was inferred with analysis of molecular variance (AMOVA) by estimating $F_{\mathrm{ST}}$ and $\Phi_{\mathrm{ST}}$ under the Tamura-Nei model with the gamma shape parameter $(\alpha=100)$. Significance was determined by 10,000 random non-parametric permutation replicates. Net sequence divergence (uncorrected P-distances) between the two breeding sites was estimated in MEGA v. 4.o (Tamura et al., 2011).

\section{Results}

In addition to our surveys we obtained 124 C. rosei records from seven museums, 48 records from herpetologists' field notes, 10 anecdotal records from local researchers and one record in the literature, spanning 110 years (1901-2011). Four of the sites had names so vague that it was not possible to identify their precise locality on the Peninsula (Fig. 1; Supplementary Table 1). Most observations were made in August and September, coinciding with the breeding season. Since 1983 all recorded attempts to find the toad at two previously well-known breeding sites on Table Mountain (Maclear's Beacon and Platteklip Gorge) have been negative, despite targeted surveys. Active breeding sites were reported east of the Old Cape Road (Silvermine area) and at Olifantsbos (Cape Point area) up until the 1970s. This suggests that at least four known breeding sites were not rediscovered.

During targeted surveys toads were found at only one historically known breeding site (Silvermine) and 


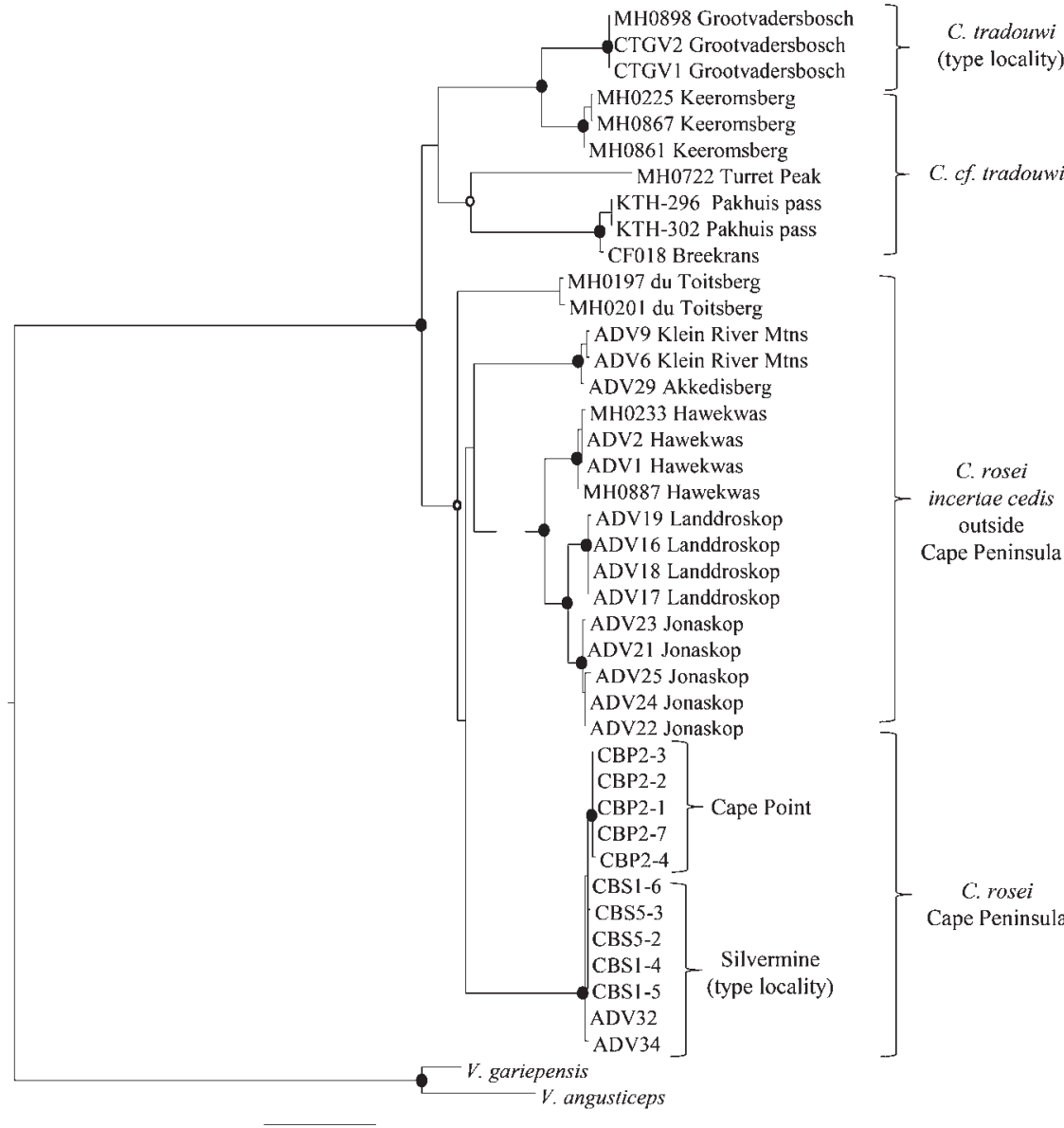

0.1 substitutions/site
FIG. 2 The best likelihood tree for Capensibufo spp., based on amplified fragments of $16 \mathrm{~S}$ and ND2 markers. Circles at each node indicate the level of support: filled circles, $\geqslant 70 \%$ likelihood bootstrap and $\geqslant 0.95$ Bayesian posterior probabilities; unfilled circles, $\geqslant 70 \%$ likelihood bootstrap. a previously unknown breeding site at Cape Point (although this was close to historical observations of single individuals), both of which had adult toads, spawn and tadpoles. At the Silvermine site there were hundreds of adult toads, whereas there were $<100$ at Cape Point (GJM \& KAT, pers. obs.; additional work is being carried out to estimate the population size). The exact locations of these two breeding sites are withheld because of the sensitive nature of these populations, and the risk of disturbance. No additional breeding sites were located despite dedicated surveys (Supplementary Table 1). We failed to find any individuals at 15 previously recorded locations of non-breeding toads. Six of the survey sites where we did not locate C. rosei have apparently suitable habitat for the species (pristine vegetation, standing pools of water). The four exceptions are Jackal's Drift (developed into a residential area), Ocean's View (invaded by alien vegetation), east of Old Cape Road (large tar road constructed during 1965-1968) and Platteklip Gorge on Table Mountain (influenced by tourism because of its location along a main footpath at the top of a popular cableway).

The phylogenetic analysis indicates that both breeding sites from the Cape Peninsula form a well-supported monophyletic lineage (Fig. 2). There were no shared haplotypes between the sites and haplotype $(h)$ and nucleotide $(\pi)$ diversity were substantially greater for the Silvermine breeding site than for Cape Point (Table 1; Supplementary Table 2). The analysis of molecular variance showed a significant difference between the two breeding sites $\left(F_{\mathrm{ST}}=0.79, \Phi_{\mathrm{ST}}=0.89, \mathrm{P}<0.001\right)$ although net sequence divergence (uncorrected P-distance) between the sites was within the range expected for populations of a single species (0.04\% for ND2). In comparison, P-distances between the Cape Peninsula populations and those from other lineages were $9-12 \%$ for $\mathrm{ND}_{2}$, similar to that usually found between amphibian species (Cunningham \& Cherry, 2004; Vences et al., 2005; Supplementary Table 3).

\section{Discussion}

Despite a dedicated search effort over a number of years only two breeding sites of $C$. rosei were located on the Cape Peninsula (Silvermine and Cape Point). Although there may be additional undiscovered populations, the species has not been observed at at least four historically known breeding sites since the 1980s, suggesting local extinction of some breeding populations. These apparent losses are of particular concern because the disappearance of 
TABLE 1 Summary statistics for the two populations of Rose's mountain toad Capensibufo rosei on the Cape Peninsula, South Africa (Fig. 1), with location, number of individuals, number of haplotypes, genetic diversity and nucleotide diversity.

\begin{tabular}{lllll}
\hline Location & No. of individuals & No. of haplotypes & Mean genetic diversity $(h) \pm$ SE & Mean nucleotide diversity $(\pi) \pm$ SE \\
\hline Silvermine & 33 & 3 & $0.322 \pm 0.097$ & $0.00063 \pm 0.00071$ \\
Cape Point & 29 & 2 & $0.069 \pm 0.063$ & $0.00012 \pm 0.00030$ \\
\hline
\end{tabular}

populations can be the prelude to species extinction (Ceballos \& Ehrlich, 2002).

Overall, the phylogenetic analysis suggests that the Cape Peninsula lineage is best treated as a separate species. Our results, together with our current knowledge of the phylogenetics and geographical distribution of C. rosei, make it clear that the taxonomy of this genus needs to be updated. However, more comprehensive sampling coupled to genetic and morphological analyses are required for a thorough assessment of the genus. Nevertheless, it is possible to confidently recognize that the Cape Peninsula lineage is sufficiently distinct to be given species status. As C. rosei was described from a holotype collected on the Cape Peninsula (Hewitt, 1926), the Cape Peninsula populations retain the name Capensibufo rosei and populations within the remainder of the distribution are placed in a state of incertae sedis. A re-evaluation of the categorization of C. rosei sensu stricto on the IUCN Red List will undoubtedly lead to a change in the current categorization of Vulnerable, given the considerably reduced Area of Occupancy and Extent of Occurrence. In turn, a new categorization will demonstrate the necessity for conservation action. There is now a more urgent need to assess the other Capensibufo spp. to clarify their taxonomic status and check for potential declines.

Although the two breeding sites (c. $20 \mathrm{~km}$ apart) on the Cape Peninsula form a single monophyletic lineage, they are differentiated at the population level by significantly high values of both $F_{\mathrm{ST}}$ and $\Phi_{\mathrm{ST}}$. There were no shared haplotypes between sites, indicating that gene flow across the $20 \mathrm{~km}$ between them is unlikely. Disruption of gene flow may be exacerbated by the apparent loss of other Cape Peninsula populations, disconnecting dispersal pathways and causing a loss of haplotypes in flanking populations (Page \& Holmes, 1998). It is important to note, however, that amphibians are usually restricted to relatively isolated populations associated with discrete breeding habitats (Beebee, 2005; Jehle et al., 2005) and can therefore exhibit strong population structuring over relatively small spatial scales. Therefore, findings could be the result of the two breeding sites being located at different ends of the original range.

Although diversity values for the Silvermine population are similar to those of other anurans (e.g. Crawford, 2003; Fitzpatrick et al., 2009; Measey \& Tolley, 2011), nucleotide diversity is an order of magnitude lower for the Cape Point population (Table 1). During the field surveys it was noted ad hoc that the number of tadpoles and quantity of spawn were lower at Cape Point than at Silvermine and no metamorphs were observed at Cape Point in 2010 or 2011. Although this could reflect natural fluctuations in population size, the apparent loss of other Cape Peninsula populations over the past 40 years raises concerns over the long-term viability of the remaining population. Declining populations often display low genetic variability, where a reduction in the effective population size causes only a small number of haplotypes to persist (Page \& Holmes, 1998; Allendorf \& Luikart, 2007). A reduction in population size can be of further detriment as a result of an increase in the amount of inbreeding, which in turn reduces the genetic diversity through drift (Ghiselin, 2002). In anurans this has been linked directly to fitness and recruitment, where lower than mean hatch, larval growth and larval survival rates are attributed to a loss of genetic variation (Rowe et al., 1999; Semlitsch et al., 2000; Rowe \& Beebee, 2003; Andersen et al., 2004). Thus, the Cape Point population is of particular conservation concern because of the lack of genetic diversity, its apparent isolation and our ad hoc observations of low population numbers.

Although it is not possible to definitively identify the cause of the apparent demise of $C$. rosei on the Cape Peninsula, it is possible to infer circumstances at some sites. The breeding site east of the Old Cape Road was probably altered by the construction of the tar road during 1965-1968. The Platteklip Gorge site on Table Mountain is influenced by human presence, with hundreds of thousands of visitors travelling by cableway to the mountaintop annually (e.g. there were $>780,000$ visitors estimated in 2002; SANParks, 2004), and there are now a major footpath and numerous side paths at the old breeding site. Additionally, beginning in the 1850 s Table Mountain was afforested with pine plantations (Huntley, 1999), although they never extended to the areas where C. rosei was historically recorded. Likewise, parts of Silvermine and Cape Point were previously invaded by alien plants, which have since been removed. Much of the natural habitat has been restored but the entire peninsula has been affected by human activity. The former plantations, invasive plant species, the existence of several major dams for water supplies, and the management practice of excluding the natural fire regime of the fynbos may have altered the habitat in subtle ways. The loss of breeding sites that have 
apparently suitable habitat, with natural vegetation and pools of water, suggests that the species has experienced some form of enigmatic decline, possibly as a result of indirect habitat alteration. However, we cannot rule out other potential causes of these enigmatic declines, such as the chytrid fungus or effects of climate change, although the former seems unlikely given that $C$. rosei has tested negative for the fungus (Tarrant et al., 2013).

Amphibian declines on the Cape Peninsula do not appear to be particularly uncommon. Eight of the 27 amphibian species that occur there are threatened (Measey, 2011) but the causes of most declines are easier to recognize. For example, four of these species (Amietophrynus pantherinus, Hyperolius horstockii, Microbatrachella capensis, Xenopus gilli) have the bulk of their distribution in and around the Cape Town metropolitan area (c. 2,500 $\mathrm{km}^{2}$, with a human population of $>3.5$ million). Within the metropolis $800 \mathrm{~km}^{2}$ is completely transformed, with a 20-fold increase in developed area since 1900 (Rebelo et al., 2011). Little original habitat remains and these species now have very small and fragmented distributions. For example, the Critically Endangered $M$. capensis, which has an estimated Area of Occupancy of only $7 \mathrm{~km}^{2}$, exists at four breeding sites only, one of which is located entirely inside a wetland at the centre of a horse racing track (Measey, 2011). Although the historical and present distribution of C. rosei is almost entirely within what is now a protected area (Table Mountain National Park, which encompasses both Silvermine and Cape of Good Hope Nature Reserves), this species still appears to have undergone a steep decline in the last several decades.

Our results suggest an urgent need for management interventions and immediate re-assessment of $C$. rosei sensu stricto for the IUCN Red List. Being historically isolated, geographically distinct and reciprocally monophyletic, both Cape Peninsula populations should be treated as separate management units. Conservation efforts should focus on the protection and growth of each individual population and the patches of suitable habitat on which they rely. Ideally, restoration of connectivity across the Cape Peninsula, possibly through reintroductions at historical sites that still retain suitable habitat, should help to reestablish gene flow and promote diversity. The specific habitat requirements and presumed restricted dispersal ability could hinder the species' ability to recover from catastrophic events. Noteworthy in this regard is the Cape Point population, which has low numbers of adults, tadpoles and spawn and unusually low genetic diversity. This population is of global conservation importance as its loss would result in this species being restricted to a single breeding site, placing it on the brink of extinction. If acted upon, the evidence and management recommendations provided by this study may contribute to the future survival of this rare Cape Peninsula endemic.

\section{Acknowledgements}

We thank South African National Parks for their support during this study, in particular Marisa de Kock, Leighan Mossop, Justin Buchman, Zishan Ebrahim, Melodie McGeoch and Carly Cowell. We also thank Peter Ryan from the Percy Fitzpatrick Institute for his assistance, and all those who provided information regarding historical records and assisted in the field: Richard Boycott, Marius Burger, Alan Channing, Michael Cunningham, Mike Cherry, Cliff Dorse, Atherton de Villiers, Angelo Lambiris, Barry Rose, Mills Tandy and John Visser. The precise locations of the two remaining breeding sites are withheld until these populations can be secured. This information can be requested from the authors for valid scientific purposes. The South African National Biodiversity Institute provided funding for this project.

\section{References}

A KaIke, H. (1973) Information theory as an extension of the maximum likelihood principle. In Second International Symposium on Information Theory (eds B.N. Petrov \& F. Csaki), pp. 267-281. Akadémiai Kiadó, Budapest, Hungary.

Allendorf, F.W. \& Luikart, G. (2007) Conservation and the Genetics of Populations. Blackwell Publishing, Oxford, UK.

Andersen, L.W., Fog, K. \& Damgaard, C. (2004) Habitat fragmentation causes bottlenecks and inbreeding in the European tree frog (Hyla arborea). Proceedings of the Royal Society of London Series B, 271, 1293-1302.

Barinaga, M. (1990) Where have all the froggies gone? Science, 247, 1033-1034.

Beebee, T.J.C. (2005) Conservation genetics of amphibians. Heredity, 95, 423-427.

Beebee, T.J.C. \& Griffiths, R.A. (2005) The amphibian decline crisis: a watershed for conservation biology? Biological Conservation, $125,271-285$.

Ceballos, G. \& Ehrlich, P.R. (2002) Mammal population losses and the extinction crisis. Science, 296, 904-907.

Collins, J.P. \& Storfer, A. (2003) Global amphibian declines: sorting the hypotheses. Diversity and Distributions, 9, 89-98.

Crawford, A.J. (2003) Huge populations and old species of Costa Rican and Panamanian dirt frogs inferred from mitochondrial and nuclear gene sequences. Molecular Ecology, 12, 2525-2540.

Cunningham, M. \& Cherry, M.I. (2004) Molecular systematics of African 20-chromosome toads (Anura: Bufonidae). Molecular Phylogenetics and Evolution, 32, 671-685.

Delvinquier, B.L.J., Markus, M.B. \& Passmore, N.I. (1991a) Opalinidae in African Anura. I. Genus Opalina. Systematic Parasitology, 19, 119-146.

Delvinquier, B.L.J., Markus, M.B. \& Passmore, N.I. (1991b) Opalinidae in African Anura. II. Genera Protozelleriella n. g. and Zelleriella. Systematic Parasitology, 19, 159-185.

Delvinquier, B.L.J., Markus, M.B. \& Passmore, N.I. (1995) Opalinidae in African Anura. IV. Genus Protoopalina. Systematic Parasitology, 30, 81-120.

De Villiers, A.L. (2004) Capensibufo rosei (Hewitt, 1926). In Atlas and Red Data Book of the Frogs of South Africa, Lesotho and Swaziland (eds L.R. Minter, M. Burger, J.A. Harrison, H.H. Braack, P.J. Bishop \& D. Kloepfer), pp. 87-90. Smithsonian Institution, Washington, DC, USA. 
Drummond, A.J., Ashton, B., Cheung, M., Heled, J., Kearse, M., Moir, R. et al. (2009) Geneious Pro v. 4.7.

Excoffier, L., Laval, G. \& Schneider, S. (2005) Arlequin (version 3.0): an integrated software package for population genetics data analysis. Evolutionary Bioinformatics, 1, 47-50.

Fitzpatrick, S.W., Brasileiro, C. A., Haddad, C.F.B. \& ZAMUDiO, K.R. (2009) Geographical variation in genetic structure of an Atlantic Coastal Forest frog reveals regional differences in habitat stability. Molecular Ecology, 18, 2877-2896.

Ghiselin, M.T. (2002) Species concepts: the basis for controversy and reconciliation. Fish and Fisheries, 3, 151-160.

Grandison, A.G.C. (1980) A new genus of toad (Anura: Bufonidae) from the Republic of South Africa with remarks on its relationships. Bulletin of the British Museum of Natural History (Zoology), 39, 293-298.

Hewitt, J. (1926) Descriptions of new and little-known lizards and batrachians from South Africa. Annals of the South African Museum, 20, 413-431.

Holsinger, K.E. \& Weir, B.S. (2009) Genetics in geographically structured populations: defining, estimating and interpreting $\mathrm{F}_{\mathrm{ST}}$. Nature Reviews Genetics, 10, 639-650.

Huntley, B.J. (1999) South Africa's experience regarding alien species: impacts and controls. In Invasive Species and Biodiversity Management (eds O.T. Sandlund, P.J. Schei \& Å. Viken), pp. 363-373. Kluwer Academic Publishers, Dordrecht, The Netherlands.

Jehle, R., Burke, T. \& Arntzen, J.W. (2005) Delineating fine-scale genetic units in amphibians: probing the primacy of ponds. Conservation Genetics, 6, 227-234.

Kress, W.J., Miller, S.E., Krupnick, G.A. \& Lovejoy, T.E. (2001) Museum collections and conservation efforts. Science, 291, 828-829. Measey, G.J. (ed.) (2011) Ensuring a Future for South Africa's Frogs: a Strategy for Conservation Research. SANBI Biodiversity Series 19. South African National Biodiversity Institute, Pretoria, South Africa.

Measey, G.J. \& Tolley, K.A. (2011) Investigating the cause of the disjunct distribution of Amietophrynus pantherinus, the Endangered South African western leopard toad. Conservation Genetics, 12, 61-70.

Measey, G.J., Weldon, C., Morgon, D., Channing, A., Harvey, J. \& Turner, T. (2011) Conservation and ecological studies. In Ensuring a Future for South Africa's Frogs: a Strategy for Conservation Research, SANBI Biodiversity Series 19 (ed. G.J. Measey), pp. 18-28. South African National Biodiversity Institute, Pretoria, South Africa.

Miller, M.A., Pfeiffer, W. \& Schwartz, T. (2010) Creating the CIPRES Science Gateway for inference of large phylogenetic trees. Proceedings of the Gateway Computing Environments Workshop (GCE), 14 November 2010, New Orleans, USA, 1-8.

Minter, L.R., Burger, M., Harrison, J.A., BraAck, H.H., Bishop, P.J. \& Kloepfer, D. (2004) Atlas and Red Data Book of the Frogs of South Africa, Lesotho and Swaziland. Smithsonian Institute, Washington, DC, USA.

Page, R.D.M. \& Holmes, E.C. (1998) Molecular Evolution: A Phylogenetic Approach. Blackwell Publishing, Oxford, UK.

Palumbi, S.R., Martin, A., Romano, W., McMillan, O., Stice, L. \& Grabows KI, G. (1991) The Simple Fool's Guide to PCR. University of Hawaii, Honolulu, USA.

Pechmann, J.H.K., Scott, D.E., Semlitsch, R.D., Caldwell, J.P., Vitt, L.J. \& Whitfield, G.J. (1991) Declining amphibian populations: the problem of separating human impacts from natural fluctuations. Science, 253, 892-895.

Posada, D. (2008) jModelTest: phylogenetic model averaging. Molecular Biology and Evolution, 25, 1253-1256.
Pounds, J.A. \& CRump, M.L. (1994) Amphibian declines and climate disturbance: the case of the golden toad and harlequin frog. Conservation Biology, 8, 72-85.

Rambaut, A. \& Drummond, A.J. (2007) Tracer v.1.4.1.

Rebelo, A.G., Holmes, P.M., Dorse, C. \& Wood, J. (2011) Impacts of urbanization in a biodiversity hotspot: conservation challenges in Metropolitan Cape Town. South African Journal of Botany, 77, 20-35.

Ronquist, F. \& Huelsenbeck, J.P. (2003) MrBayes 3: Bayesian phylogenetic inference under mixed models. Bioinformatics, 19, 1572-1574.

Rose, W. (1950) The Reptiles and Amphibians of Southern Africa. Maskew Miller, Cape Town, South Africa.

Rowe, G. \& Beebee, T.J.C. (2003) Population on the verge of a mutational meltdown? Fitness costs of genetic load for an amphibian in the wild. Evolution, 57, 177-181.

Rowe, G., Beebee, T.J.C. \& Burke, T. (1999) Microsatellite heterozygosity, fitness and demography in natterjack toads Bufo calamita. Animal Conservation, 2, 85-92.

SA-Frog (South African Frog Re-assessment Group), IUCN SSC Amphibian Specialist Group (2010) Capensibufo rosei. In IUCN Red List of Threatened Species v. 2013.2. Http://www. iucnredlist.org [accessed 3 December 2013].

SANParks (South African National Parks) (2004) The Economic Contribution of Table Mountain National Park. South African National Parks, Cape Town, South Africa.

Semlitsch, A.R.D., Bridges, C.M. \& Welch, A.M. (2000) Genetic variation and a fitness tradeoff in the tolerance of gray treefrog ( Hyla versicolor) tadpoles to the insecticide carbaryl. Oecologia, 125, 179-185.

Skelly, D.K., Yurewicz, K.L., Werner, E.E. \& Relyea, R.A. (2003) Estimating decline and distributional change in amphibians. Conservation Biology, 17, 744-751.

Stamata KIs, A. (2006) RAxML-VI-HPC: maximum likelihood-based phylogenetic analyses with thousands of taxa and mixed models. Bioinformatics, 22, 2688-2690.

Stamatakis, A., Hoover, P. \& Rougemont, J. (2008) A rapid bootstrap algorithm for the RAxML web servers. Systematic Biology, 57, 758-771.

Stuart, S.N., Chanson, J.S., Cox, N.A., Young, B.E., Rodrigues, A.S.L., Fischman, D.L. \& Waller, R.W. (2004) Status and trends of amphibian declines and extinctions worldwide. Science, 309, 1783-1786.

Tamura, K. \& Nei, M. (1993) Estimation of the number of nucleotide substitutions in the control region of mitochondrial DNA in humans and chimpanzees. Molecular Biology and Evolution, 10, 512-526.

Tamura, K., Peterson, D., Peterson, N., Stecher, G., Nei, M. \& Kumar, S. (2011) MEGA5: molecular evolutionary genetics analysis using maximum likelihood, evolutionary distance, and maximum parsimony methods. Molecular Biology and Evolution, 28, 2731-2739.

Tarrant, J., Cilliers, D., du Preez, L.H., Weldon, C. (2013) Spatial assessment of amphibian chytrid fungus (Batrachochytrium dendrobatidis) in South Africa confirms endemic and widespread infection. PLoS ONE 8(7): e69591.

Tolley, K.A., De Villiers, A.L., Cherry, M.I. \& Measey, G.J. (2010) Isolation and high genetic diversity in dwarf mountain toads (Capensibufo) from South Africa. Biological Journal of the Linnean Society, 100, 822-834.

Vences, M., Thomas, M., van der Meijden, A., Chiari, Y. \& Vieites, D.R. (2005) Comparative performance of the $16 \mathrm{~S}$ rRNA gene in DNA barcoding of amphibians. Frontiers in Zoology, 2, 5 . 


\section{Biographical sketches}

The authors for this article are based at various institutions in South Africa and collaborated on this project under the Applied Biodiversity Division's Research Strategy for the South African National Biodiversity Institute. Part of this work was carried out within the context of an MSc study for ERC in the Conservation Biology Masters Programme at the University of Cape Town. KAT and GJM are dedicated to producing research that can be used towards increasing protection of South Africa's amphibians, and both are involved in Red Listing for amphibians in the region. 